University of South Carolina

Scholar Commons

$5-14-2009$

\title{
Tobacco Mosaic Virus Templated Synthesis of One Dimensional Inorganic-Polymer Hybrid Fibres
}

\author{
Jianhua Rong \\ Fiona Oberbeck \\ Xinnan Wang \\ Xiaodong Li \\ University of South Carolina - Columbia, lixiao@cec.sc.edu \\ Jerry Oxsher
}

See next page for additional authors

Follow this and additional works at: https://scholarcommons.sc.edu/emec_facpub

Part of the Applied Mechanics Commons

\section{Publication Info}

Published in Journal of Materials Chemistry, Volume 19, Issue 18, 2009, pages 2841-2845.

(C) Journal of Materials Chemistry 2009, Royal Society of Chemistry.

This article cannot be redistributed or further made available.

This article was first published by the Royal Society of Chemistry and can be found at http://dx.doi.org/ 10.1039/B901130G

Rong, J., Oberbeck, F., Wang, X., Li, X., Oxsher, J., Niu, Z., \& Wang, Q. (14 May 2009). Tobacco Mosaic Virus Templated Synthesis of One Dimensional Inorganic-Polymer Hybrid Fibres. Journal of Materials Chemistry, 19 (18), 2841 - 2845. http://dx.doi.org/10.1039/B901130G

This Article is brought to you by the Mechanical Engineering, Department of at Scholar Commons. It has been accepted for inclusion in Faculty Publications by an authorized administrator of Scholar Commons. For more information, please contact digres@mailbox.sc.edu. 


\section{Author(s)}

Jianhua Rong, Fiona Oberbeck, Xinnan Wang, Xiaodong Li, Jerry Oxsher, Zhongwei Niu, and Qian Wang 


\title{
Tobacco mosaic virus templated synthesis of one dimensional inorganic- polymer hybrid fibres $\dagger$
}

\author{
Jianhua Rong, ${ }^{a b}$ Fiona Oberbeck, ${ }^{b}$ Xinnan Wang, ${ }^{c}$ Xiaodong Li, ${ }^{d}$ Jerry Oxsher, ${ }^{b}$ Zhongwei Niu ${ }^{* b}$ \\ and Qian Wang ${ }^{* b}$
}

\author{
Received 19th January 2009, Accepted 13th February 2009 \\ First published as an Advance Article on the web 16th March 2009 \\ DOI: $10.1039 / \mathrm{b} 901130 \mathrm{~g}$
}

\begin{abstract}
Inorganic-polymer hybrid nanofibres were prepared by using a rod-like tobacco mosaic virus (TMV) as a template. With tetraethylorthosilicate (TEOS) as a precursor, long silica-coated TMV fibres were formed via a head-to-tail assembly, which showed a substantial increase of the elastic modulus. Furthermore, homogenous titania-TMV hybrid fibres could be prepared using polyaniline-coated TMV fibres as a template, which were used to form a composite film that was able to sense liquefied petroleum gases.
\end{abstract}

\section{Introduction}

The synthesis of polymer-inorganic hybrids has attracted increasing attention due to their intriguing physical properties and many important applications. ${ }^{1-3}$ These composites not only combine the advantageous properties of inorganic materials and polymers, but also exhibit many new characteristics that singlephase materials do not have. In particular, a one dimensional (1D) composite nanowire is one of the most important components for the development of nanoscale electronic devices, sensors, and energy storage units. ${ }^{4,5}$ Among all available synthetic strategies for 1D nanomaterials, template synthesis is one of the major methods. ${ }^{6-9}$ On the other hand, biological nanoparticles, such as viruses and self-assembled protein complexes, allow genetic manipulation and chemospecific bioconjugation at near-atomic scale, providing highly promising opportunities as templates for the fabrication of nanoscale materials with novel functionalities. ${ }^{10-14}$ Previously, we reported a simple approach to prepare a $1 \mathrm{D}$ conducting polymer nanowire using the rod-like tobacco mosaic virus (TMV) as a template. ${ }^{7,15}$ In this paper, we focus on the synthesis and characterization of $\mathrm{SiO}_{2}-\mathrm{TMV}$ and titania-conducting polymer-TMV composite nanofibres using TMV as a template.

Native TMV particles possess a unique tube-like structure and distinctive physiochemical properties, which have made them a robust and attractive platform for the deposition of inorganic materials on either the interior or the exterior surface to form 1D nanostructures. ${ }^{16-25}$ The virus is assembled from 2130 identical coat proteins arranged helically around a single strand of RNA.

${ }^{a}$ Department of Materials Science and Engineering, Jinan University, Guangzhou, 130025, P. R. China

${ }^{b}$ Department of Chemistry and Biochemistry and Nanocenter, University of South Carolina, Columbia, SC, 29208, USA. E-mail: wang@mail.chem.sc. edu; niu.z@mail.chem.sc.edu; Tel: +01-803-777-2680

'Department of Mechanical Engineering and Applied Mechanics, North Dakota State University, Fargo, ND, 58108, USA

${ }^{d}$ Department of Mechanical Engineering, University of South Carolina, Columbia, SC, 29208, USA

$\dagger$ Electronic supplementary information (ESI) available: AFM images. See DOI: $10.1039 / \mathrm{b} 901130 \mathrm{~g}$
The entire particle measures $300 \mathrm{~nm}$ in length and $18 \mathrm{~nm}$ in diameter, and can be isolated from infected tobacco plants in gram quantities with relative ease. The virion remains intact at temperatures up to $60^{\circ} \mathrm{C}$ and at $\mathrm{pH}$ values between 2 and $10 .^{26,27}$ Moreover, recent studies have shown that the surface properties of TMV can be chemically ${ }^{\mathbf{2 8 , 2 9}}$ or genetically ${ }^{30,31}$ manipulated without interfering with the integrity and morphology of the virus. Evidently, TMV-based materials have already shown great potential in nanoelectronics and other applications. ${ }^{32,33}$

In the fabrication of TMV-templated water-dispersible polyaniline (PANi) nanowires, ${ }^{7,8}$ a head-to-tail assembly mechanism was proposed based on a time-resolved small angle X-ray scattering study, where the assembly was assisted by the polymerization of aniline on a TMV surface to form long 1D nanofibres at low concentrations. ${ }^{15}$ In this paper, we show that silica $\left(\mathrm{SiO}_{2}\right)$ or titania $\left(\mathrm{TiO}_{2}\right)$-coated composite fibres are readily prepared with native TMV or PANi-coated TMV (PANi-TMV) fibres as templates. The structure of these composite fibres was characterized by transmission electron microscopy (TEM) and atomic force microscopy (AFM). By introducing $\mathrm{TiO}_{2}$ into PANi-TMV composite fibres, it was possible to increase the elastic modulus, and at the same time to maintain the conductivity of PANi. Due to the good processibility of these composite fibres, they were easily fabricated into a thin film that could be used to sense liquefied petroleum gases (LPG).

\section{Experimental}

\section{Materials}

Tetraethylorthosilicate (TEOS), tetrabutyl titanate (TBT), acrylacetone, ammonium persulfate (APS) and poly(sulfonated styrene) (PSS) were used as received. Aniline was distilled before use. HPLC grade ethanol and deionized water were used in all preparations. The purification of TMV was described in our previous report. ${ }^{15}$

\section{Characterization}

A $20 \mu \mathrm{L}$ sample solution $\left(0.2 \mathrm{mg} \mathrm{mL} \mathrm{mL}^{-1}\right)$ was deposited onto a 300-mesh carbon-coated copper grid. After $2 \mathrm{~min}$, the grid was 
stained with $20 \mu \mathrm{L}$ of $2 \%$ uranyl acetate and was characterized with a JEOX 100 CX II TEM. Tapping mode AFM images were obtained under ambient conditions using a NanoScope IIIA MultiMode microscope (Veeco). $\mathrm{Si}_{3} \mathrm{~N}_{4}$ tips with a resonance frequency of approximately $300 \mathrm{kHz}$, a spring constant of about $40 \mathrm{~N} \mathrm{~m}^{-1}$, and a scan rate of $0.5 \mathrm{~Hz}$ were used. UV-Vis absorption studies were performed using an Agilent $8453 \mathrm{UV}-\mathrm{V}$ is spectrometer.

\section{Preparation of $\mathrm{SiO}_{2}-\mathrm{TMV}$ and $\mathrm{TiO}_{2}-\mathrm{TMV}$ nanocomposites}

A solution of TEOS $(10 \mu \mathrm{L})$ or TBT-acetylacetone $(\mathrm{v} / \mathrm{v}=1: 1$, $10 \mu \mathrm{L})$ in ethanol $(100 \mu \mathrm{L})$ was added and mixed with TMV (1 $\mathrm{mg} \mathrm{mL}^{-1}, 4 \mathrm{~mL}$ ). The solution $\mathrm{pH}$ was adjusted to 4 using $0.01 \mathrm{M}$ $\mathrm{HCl}$ and $0.01 \mathrm{M} \mathrm{NaOH}$. The reaction mixture was incubated at room temperature overnight, followed by centrifugation at $12000 \mathrm{~g}$ for $15 \mathrm{~min}$. The resulting pellet was resuspended in deionized water. The centrifugation and resuspension operation was repeated three times to obtain pure inorganic-TMV composite fibres.

\section{Synthesis of PSS-PANi-TMV long fibres (PTLF) ${ }^{7}$}

In a typical synthesis, distilled aniline $(10 \mu \mathrm{L})$ and APS solution (10 $\left.\mathrm{mg} \mathrm{mL}^{-1}, 1 \mathrm{~mL}\right)$ were added to TMV solution $\left(1 \mathrm{mg} \mathrm{mL}^{-1}, 4\right.$ $\mathrm{mL}$ ) consecutively. The solution $\mathrm{pH}$ was adjusted to 6.5 with 0.01 $\mathrm{M} \mathrm{HCl}$ and $0.01 \mathrm{M} \mathrm{NaOH}$. The reaction mixture was incubated at room temperature for $24 \mathrm{~h}$ before PSS (20 mg) and aniline (10 $\mu \mathrm{L})$ were added. The $\mathrm{pH}$ of the reaction solution was adjusted to 4 and the reaction mixture was incubated at room temperature for $24 \mathrm{~h}$. Upon dialysis against nanopure water with $M_{\mathrm{w}} 300000$ cutoff dialysis tube (Pierce), all the small molecules and free polymers were removed to obtain pure PSS-PANi-TMV long nanofibres (denoted PTLF).

\section{Synthesis of $\mathrm{TiO}_{2}-\mathrm{PTLF}$ composite nanofibres}

The solution $\mathrm{pH}$ of a PTLF solution $\left(0.5 \mathrm{mg} \mathrm{mL}^{-1}, 4 \mathrm{~mL}\right)$ was adjusted to 4 before TBT-acetylacetone $(\mathrm{v} / \mathrm{v}=1: 1,5 \mu \mathrm{L})$ in ethanol $(100 \mu \mathrm{L})$ was added. The reaction solution was then incubated for $24 \mathrm{~h}$ at room temperature to form a clear solution. Acetylacetone is used here as the chelating agent to decrease the sol-gel speed of TBT. The reaction mixture was centrifuged at $12000 \mathrm{~g}$ for $15 \mathrm{~min}$ and the resultant pellet was rinsed immediately with pure water. This step was repeated three times to get the pure composite nanofibres.

\section{LPG sensing properties of composite film}

The $\mathrm{TiO}_{2}-\mathrm{PTLF}$ film was deposited on a glass slide with two ends coated with gold as electrodes. The LPG sensing properties of the film were studied using a home-made gas sensing unit, composed of a small plastic chamber with a gas inlet and outlet. The thin film was installed inside the chamber tightly. Through the external connections, current-voltage characteristics were recorded using a potentiostat. In order to determine the response of the film to LPG, the current was recorded with time by holding the potential at $5.0 \mathrm{~V}$ in the absence and presence of the LPG alternately.

\section{Results and discussion}

TMV head-to-tail ordered assembly has often been observed as a product of complementary hydrophobic interactions between the dipolar ends of the helical structure. ${ }^{8,34}$ In particular, the 1D assembly is dramatically favored in an acidic environment due to the minimization of the repulsion between the carboxylic residues at the assembly interface. ${ }^{8}$ Previously, we reported that TMV head-to-tail self-assembly could be favored by aniline polymerization and formed $1 \mathrm{D}$ homogenous long fibres because of the charge-charge interaction. ${ }^{8}$ It has been extensively reported that TMV could be used as a template to bind different metals or metal oxides on its surface and to synthesize 1D inorganic-TMV composites. ${ }^{16-21}$ The synthesis of $\mathrm{SiO}_{2}-\mathrm{TMV}$ composite fibres has also been studied under strong acid conditions in ethanol. ${ }^{22}$ Recently, the deposition of silica on the surface of TMV and an E50Q mutant of TMV was also achieved at a higher $\mathrm{pH}(>7) .{ }^{35} \mathrm{In}$ both studies, the length of composite fibre
Path A

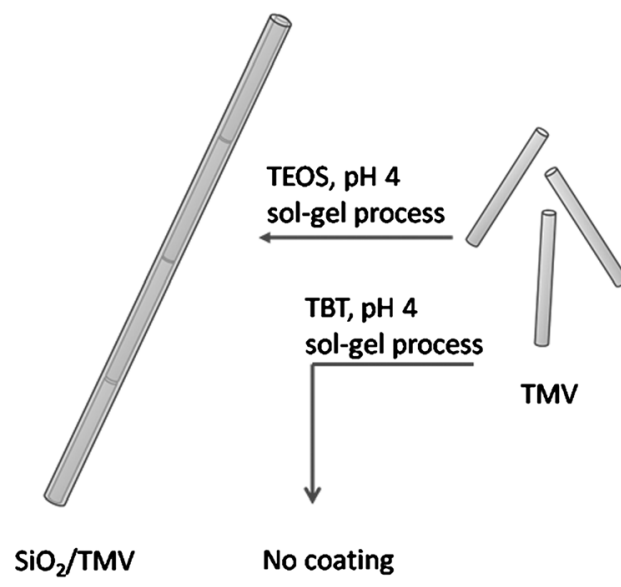

Path B

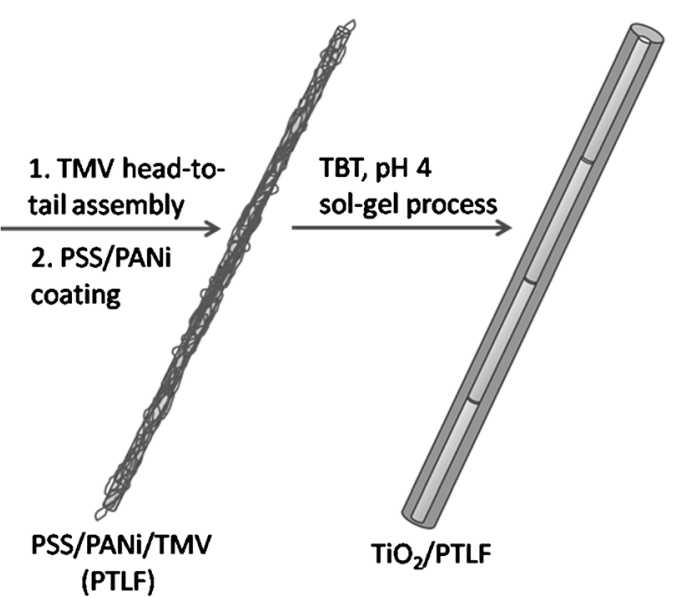

Scheme 1 Schematic demonstration of the fabrication of composite nanofibres using TMV (pathway A) or long PANi-coated TMV fibres (pathway B) as a template. 
was determined by the original template, although some longer fibres were observed. We hypothesize that, under weak acidic conditions, TEOS can accumulate on the surface of TMV due to the non-covalent interactions between TMV and TEOS while the TMV head-to-tail assembly is favored (Scheme 1, pathway A). Therefore, using a slow sol-gel process, a thin layer of silica coating can be generated on the surface of TMV, and fix the long fibre-like structure.

In a typical experiment, a solution of TEOS in ethanol was added and mixed with a TMV solution. The reaction mixture was kept at room temperature overnight at $\mathrm{pH} 4$ to afford $\mathrm{SiO}_{2-}$ TMV composite fibres. The formation of nanowires was confirmed by TEM. In contrast to native TMV, the length of the $\mathrm{SiO}_{2}-\mathrm{TMV}$ composite fibres can be as long as $\sim 3 \mu \mathrm{m}$ (Fig. 1a, 1b). For AFM analysis, the reaction solution was directly diluted 10 times with pure water and spin-coated on a silicon wafer. Fig. 1c and 1d show the typical AFM images of the $\mathrm{SiO}_{2}-\mathrm{TMV}$ composite fibres. Both height and phase images clearly show that the length of composite fibre is much longer than $300 \mathrm{~nm}$, the original length of native TMV. Only very few bulk silica particles or clusters could be detected by TEM and AFM. Energy dispersive spectroscopy (EDX) of the composite fibres was performed. As shown in Fig. 1a inset, after coating, a significant $\mathrm{Si}$ peak appears which clearly shows the silica was successfully coated on the TMV surface.

The mechanical characterization of $\mathrm{SiO}_{2}-\mathrm{TMV}$ fibres was done through AFM based nanoindentation tests. The testing method is detailed elsewhere. ${ }^{36}$ Fig. 2 reveals the AFM probe cantilever deflection history as the Z-piezo expands vertically towards the individual $\mathrm{SiO}_{2}-\mathrm{TMV}$ fibres. A typical indentation curve on a $\mathrm{SiO}_{2}-\mathrm{TMV}$ fibre can be divided into four stages (i-iv). It was observed (in stage i) that the AFM tip approached the sample surface with no generation of deflection, and then gave rise to
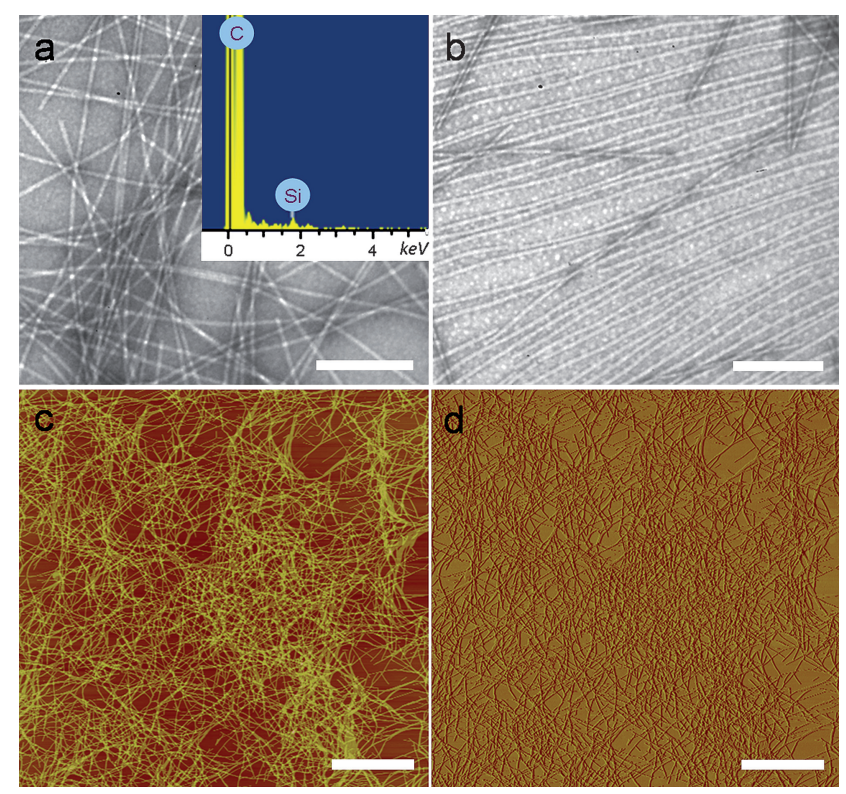

Fig. 1 (a) and (b) TEM image of $\mathrm{SiO}_{2}-\mathrm{TMV}$ composite fibre. Inset: corresponding EDX spectrum showing Si peak (C peaks are from TEM grid). (c) and (d) AFM height and phase images of $\mathrm{SiO}_{2}-\mathrm{TMV}$ composite fibres. Scale bars are $500 \mathrm{~nm}$ for (a) and (b); and $4 \mu \mathrm{m}$ for (c) and (d).

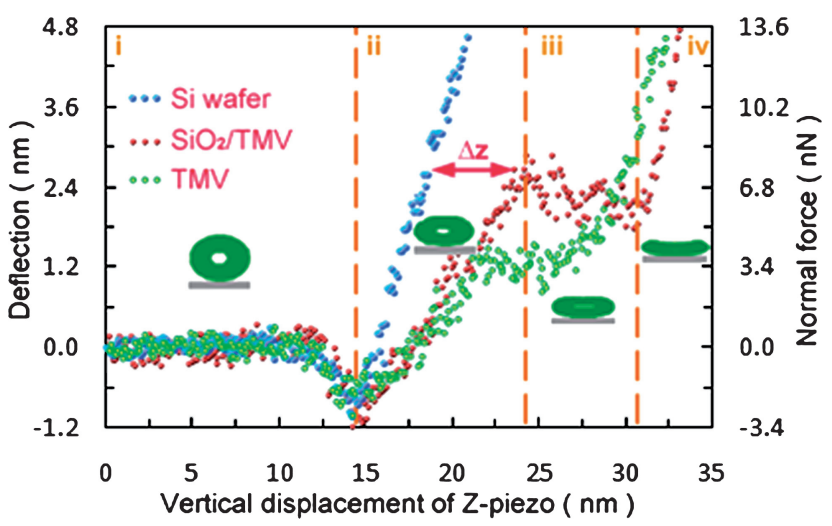

Fig. 2 Curves of the AFM probe cantilever deflection versus vertical displacement of Z-piezo. Indentation depth $\Delta z$ is the displacement difference of Z-piezo between the $\mathrm{Si}$ wafer and $\mathrm{SiO}_{2}-\mathrm{TMV}$ or TMV fibre in the elastic deformation region. The inset cartoons show the cross sectional views of the indentation process.

a sudden snap-in, which was due to the adhesive force between the tip and sample surface, and was brought into contact with the sample. The force (F) due to adhesion was measured to be $\sim 3.4$ $\mathrm{nN}$, assuming that it was constant and static for the duration of a given measurement. As the tip was continuously pressed against the sample surface within an $\sim 8 \mathrm{~nm}$ range (stage ii), the total force exerted on the sample then increased linearly from negative to positive, followed by a non-linear response (stage iii). The inner cavity of the fibre was further squeezed against the $\mathrm{Si}$ wafer (shown in stage iv), where substrate effects became significant. By establishing a finite element model in ANSYS and tailoring the elastic modulus to fit the slope of the linear portion of the $F-\Delta z$ relationship, the elastic modulus was then determined. The elastic modulus of $\mathrm{SiO}_{2}-\mathrm{TMV}$ was calculated to be $1.29 \pm 0.3 \mathrm{GPa}$, compared with $1.1 \pm 0.2 \mathrm{GPa}$ for TMV. The nuance in elastic moduli between $\mathrm{SiO}_{2}-\mathrm{TMV}$ and TMV nanofibres suggests that the ultra thin silica coating layer has the capability of tailoring the mechanical properties of these fibres.

For titania, however, due to the low charge on the surface of the TMV in acidic conditions and the fast speed sol-gel process of titania, it was difficult for titania to be coated on the TMV surface using the direct coating method (pathway A in Scheme 1). Instead, a two-step procedure was developed to prepare titania-TMV composite nanofibres (pathway B in Scheme 1). First, 1D composite fibres, denoted PTLF, were prepared according to our previous work. ${ }^{7}$ Incubation of aniline and TMV at neutral $\mathrm{pH}$ resulted in the PANi-coated TMV fibres (denoted as PANi-TMV). The formation of highly branched PANi at neutral reaction $\mathrm{pH}$ prevented lateral association of PANi-TMV fibres due to the increase of steric repulsion (Fig. 3b). ${ }^{15}$ Such nanofibres exhibit homogeneous diameters and high aspect ratios, but no conductivity due to the branched structures of PANi. When PANi-TMV was treated with PSS, additional aniline and APS at pH 4, long 1D fibres (PTLF) were produced with increased diameters (Fig. 3c). The highly negatively charged PSS was used here both as the dopant acid to enhance the conductivity of PANi and to improve the stability of composite fibres in aqueous solution. Additionally, the coating of PSS can promote the absorption of the TBT onto the composite fibre surface and restrict the sol-gel process in the PSS-PANi layer. 


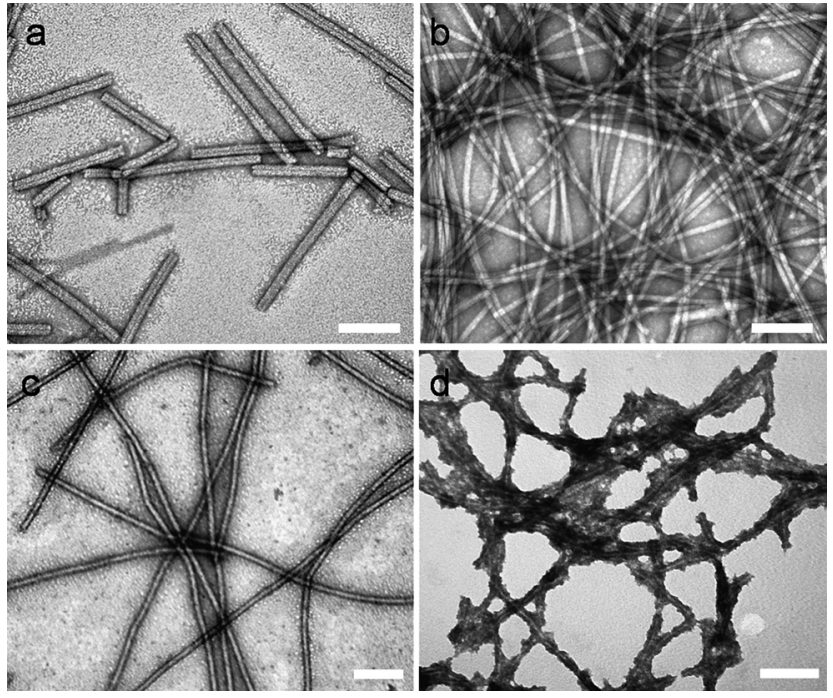

Fig. 3 TEM images of (a) wt-TMV; (b) PANi-TMV; (c) PTLF; (d) $\mathrm{TiO}_{2}-\mathrm{PTLF}$ composite nanofibres. Scale bars are $100 \mathrm{~nm}$ for (a), and 200 $\mathrm{nm}$ for (b), (c) and (d).

With long PTLF composite fibres as templates, titania-coated fibres can be readily prepared. In order to lower the sol-gel speed of TBT and restrict the reaction on the surface of PTLF composite fibres, acetylacetone was used as the chelator to add into the reaction (for details see Experimental section). As shown in Fig. 3d, it is clear that titania-coated long fibres, denoted $\mathrm{TiO}_{2}-\mathrm{PTLF}$, are thicker with a more coarse surface than PTLF templates. Furthermore, AFM analyses showed that $\mathrm{TiO}_{2}$ was coated on the long viral fibres instead of being codeposited with the fibres (Fig. S1, ESI $\dagger$ ). The length of titania composite fibres can reach several micrometres. Since the synthesis was performed at room temperature, only amorphous titania was obtained.

As shown in Fig. 4, the UV-Vis absorbance peak at $260 \mathrm{~nm}$, observed from all the samples, is attributed to the absorbance of TMV (the solid line). Thorough dialysis against deionized water gave a PTLF composite fibre sample with four absorption peaks

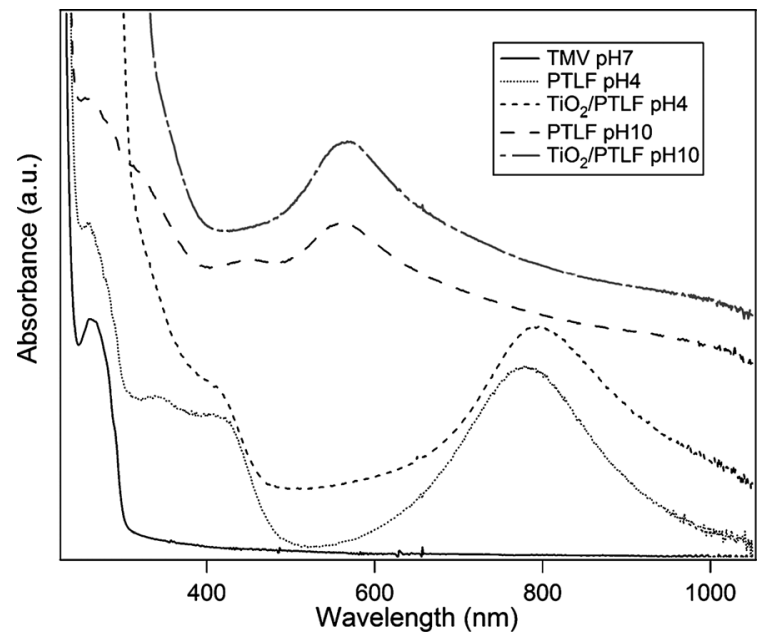

Fig. 4 UV-Vis spectra of native TMV and composite fibres. (ca. $260 \mathrm{~nm}, 320 \mathrm{~nm}, 420 \mathrm{~nm}$ and $\sim 800 \mathrm{~nm}$ ) (dotted line). Three absorption bands are observed, which is consistent with the emeraldine salt form of PANi. Two absorption peaks at about 420 and $823 \mathrm{~nm}$ are attributed to polaron band transitions, and the peak at $320 \mathrm{~nm}$ is due to the $\delta-\delta^{*}$ transition of the benzenoid rings. These peaks indicate that PANi is in its conducting form, similar to that obtained when using chemical or electrochemical methods. With the addition of $\mathrm{TiO}_{2}$, two main absorption peaks at $440 \mathrm{~nm}$ and $800 \mathrm{~nm}$ still remain, which means the PANi remains in its conducting form. Due to the absorbance of $\mathrm{TiO}_{2}$, the absorption peaks of TMV at $260 \mathrm{~nm}$ and PANi at $320 \mathrm{~nm}$ cannot be observed. When measured at $\mathrm{pH} 10$, the disappearance of the peak at $800 \mathrm{~nm}$ and the appearance of a new strongly absorbing peak at $c a .570 \mathrm{~nm}$ is observed, which can be attributed to the formation of the emeraldine base state of PANi.

Among inorganic materials, $\mathrm{TiO}_{2}$ is one of the most attractive and extensively used materials for the detection of $\mathrm{H}_{2}, \mathrm{NH}_{3}, \mathrm{NO}_{2}$ and LPG gases. ${ }^{37-39}$ Therefore, our $\mathrm{TiO}_{2}-\mathrm{PTLF}$ composite fibres will have strong potential for sensor applications due to their conductivity (from PANi components) and water-dispersability. By a simple coating operation on a glass slide, a conducting film of $\mathrm{TiO}_{2}-\mathrm{PTLF}$ was prepared. The fibres were distributed evenly within the thin film as shown in Fig. 5a and b. The LPG sensing properties of the film were studied using a home-made gas sensing unit, composed of a small plastic chamber with a gas inlet and outlet. The thin film was installed inside the chamber tightly. Through the external connections, current-voltage characteristics were recorded using a potentiostat. Fig. $5 \mathrm{c}$ shows the LPG response (the typical $I-t$ characteristics) of the $\mathrm{TiO}_{2}-\mathrm{PTLF}$ film exposed to LPG and air alternately at an applied potential of $+5.0 \mathrm{~V}$ at room temperature. As the film was exposed to LPG,
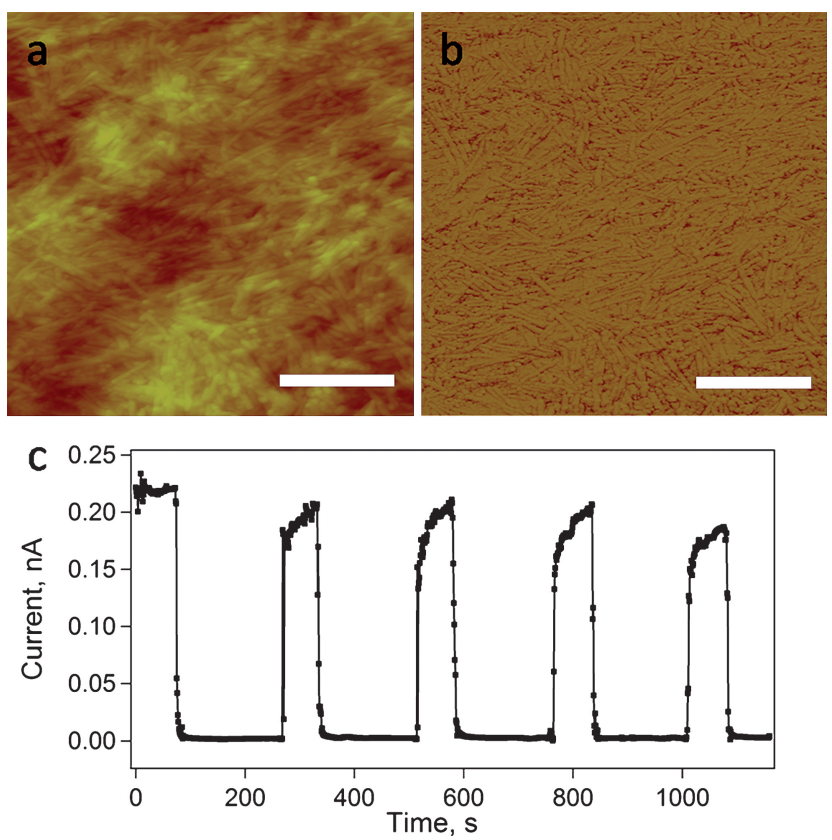

Fig. 5 (a) and (b) AFM height and phase images of thin films coated with $\mathrm{TiO}_{2}-\mathrm{PTLF}$ composite fibres. Scale bars are $500 \mathrm{~nm}$. (c) The response of the $\mathrm{TiO}_{2}-\mathrm{PTLF}$ thin film when being exposed to LPG at 25 ${ }^{\circ} \mathrm{C}$. The current was recorded over time by holding the potential at $5.0 \mathrm{~V}$ in the absence and presence of the LPG alternately. 
the forward current drastically decreased in comparison to that of air, which was similar to the result observed for $\mathrm{NH}_{3}$ and $\mathrm{CO}$ gases. ${ }^{39}$ The decrease in current was attributed to the absorption of gas on the surface of the film resulting in an increase in the resistance of PANi. The current then increased immediately when LPG was replaced by air, exhibiting a faster response and a shorter recovery time. The response of the film could be repeated for multiple cycles, which indicates the good reproducibility for the sensing activity of the film.

\section{Conclusions}

Composite fibres of $\mathrm{SiO}_{2}$ or $\mathrm{TiO}_{2}$-coated $\mathrm{TMV}$ have been synthesized using TMV or PANi-coated TMV fibres as templates. TMV could self-assemble into a long fibre structure in a head-to-tail fashion during the sol-gel process at $\mathrm{pH} 4$ using TEOS as the starting material. The length of the $\mathrm{SiO}_{2}-\mathrm{TMV}$ composite fibre can be longer than $\sim 3 \mu \mathrm{m}$. The elastic modulus of the $\mathrm{SiO}_{2}-\mathrm{TMV}$ composite fibres was improved compared with wt-TMV. With a two-step procedure, long $\mathrm{TiO}_{2}$-coated composite fibres, i.e. $\mathrm{TiO}_{2}-\mathrm{PTLF}$, could be successfully prepared using conducting PANi-TMV fibres as templates. The LPG sensing properties using the $\mathrm{TiO}_{2}-\mathrm{PTLF}$ thin film were measured. The results showed that the thin film had a good sensitivity and reproducibility.

\section{Acknowledgements}

This work was supported by the US NSF, the Alfred P. Sloan Scholarship, the Camille Dreyfus Teacher Scholar Award, and the W. M. Keck Foundation. JR is thankful for the support from the National Natural Science Foundation of China (20604010).

\section{References}

1 A. B. Descalzo, R. Martinez-Manez, F. Sancenon, K. Hoffmann and K. Rurack, Angew. Chem., Int. Ed., 2006, 45, 5924-5948.

2 P. Innocenzi and B. Lebeau, J. Mater. Chem., 2005, 15, 3821-3831. 3 A. Walcarius, Chem. Mater., 2001, 13, 3351-3372.

4 F. D. Blum, S. K. Pillalamarri, L. K. Werake, J. G. Story, M. F. Bertino and A. T. Tokuhiro, Polym. Prepr., 2006, 47, 405.

5 L. J. Chen, J. Mater. Chem., 2007, 17, 4639-4643.

6 Y. S. Jung, W. Jung, H. L. Tuller and C. A. Ross, Nano Lett., 2008, 8, 3776-3780.

7 Z. Niu, J. Liu, L. A. Lee, M. A. Bruckman, D. Zhao, G. Koley and Q. Wang, Nano Lett., 2007, 7, 3729-3733.

8 Z. W. Niu, M. Bruckman, V. S. Kotakadi, J. B. He, T. Emrick, T. P. Russell, L. Yang and Q. Wang, Chem. Commun., 2006, 3019-3021. 9 J. Wang, J. H. Dai and T. Yarlagadda, Langmuir, 2005, 21, 9-12.

10 T. Douglas and M. Young, Science, 2006, 312, 873-875.

11 Y. Lin, A. Boker, J. He, K. Sill, H. Xiang, C. Abetz, X. Li, J. Wang, T. Emrick, S. Long, Q. Wang, A. Balazs and T. P. Russell, Nature, 2005, 434, 55-59.
12 C. Mao, D. J. Solis, B. D. Reiss, S. T. Kottmann, R. Y. Sweeney, A. Hayhurst, G. Georgiou, B. Iverson and A. M. Belcher, Science, 2004, 303, 213-217.

13 M. Uchida, M. T. Klem, M. Allen, P. Suci, M. Flenniken, E. Gillitzer, Z. Varpness, L. O. Liepold, M. Young and T. Douglas, Adv. Mater., 2007, 19, 1025-1042.

14 Q. Wang, T. Lin, L. Tang, J. E. Johnson and M. G. Finn, Angew. Chem., Int. Ed., 2002, 41, 459-462.

15 Z. Niu, M. A. Bruckman, S. Li, L. A. Lee, B. Lee, S. V. Pingali, P. Thiyagarajan and Q. Wang, Langmuir, 2007, 23, 6719-6724.

16 E. Dujardin, C. Peet, G. Stubbs, J. N. Culver and S. Mann, Nano Lett., 2003, 3, 413-417.

17 M. Knez, A. M. Bittner, F. Boes, C. Wege, H. Jeske, E. Maiss and K. Kern, Nano Lett., 2003, 3, 1079-1082.

18 M. Knez, A. Kadri, C. Wege, U. Gosele, H. Jeske and K. Nielsch, Nano Lett., 2006, 6, 1172-1177.

19 M. Knez, M. Sumser, A. Bittner, C. Wege, H. Jeske, T. Martin and K. Kern, Adv. Funct. Mater., 2004, 14, 116-124.

20 M. Knez, M. P. Sumser, A. M. Bittner, C. Wege, H. Jeske, D. M. P. Hoffmann, K. Kuhnke and K. Kern, Langmuir, 2004, 20, 441-447.

21 T. Rikako, M. Muraoka, M. Seki, H. Tabata and I. Yamashita, Chem. Mater., 2007, 19, 2389-2391.

22 W. Shenton, T. Douglas, M. Young, G. Stubbs and S. Mann, Adv. Mater., 1999, 11, 253-256.

23 S. Balci, A. M. Bittner, K. Hahn, C. Scheu, M. Knez, A. Kadri, C. Wege, H. Jeske and K. Kern, Electrochim. Acta, 2006, 51, 62516257.

24 S. Balci, D. M. Leinberger, M. Knez, A. M. Bittner, F. Boes, A. Kadri, C. Wege, H. Jeske and K. Kern, Adv. Mater., 2008, 20, 2195-2200.

25 S. Balci, K. Noda, A. M. Bittner, A. Kadri, C. Wege, H. Jeske and K. Kern, Angew. Chem., Int. Ed., 2007, 46, 3149-3151.

26 R. Diaz-Avalos and D. L. D. Caspar, Biophys. J., 1998, 74, 595603.

27 K. Namba and G. Stubbs, Science, 1986, 231, 1401-1406.

28 M. A. Bruckman, G. Kaur, L. A. Lee, F. Xie, J. Sepulveda, R. Breitenkamp, X. Zhang, M. Joralemon, T. P. Russell, T. Emrick and Q. Wang, ChemBio Chem, 2008, 9, 519-523.

29 T. L. Schlick, Z. Ding, E. W. Kovacs and M. B. Francis, J. Am. Chem. Soc., 2005, 127, 3718-3723.

30 M. Koo, M. Bendahmane, G. A. Lettieri, A. D. Paoletti, T. E. Lane, J. H. Fitchen, M. J. Buchmeier and R. N. Beachy, Proc. Natl. Acad. Sci. U. S. A., 1999, 96, 7774-7749.

31 H. Yi, S. Nisar, S. Y. Lee, M. A. Powers, W. E. Bentley, G. F. Payne, R. Ghodssi, G. W. Rubloff, M. T. Harris and J. N. Culver, Nano Lett., 2005, 5, 1931-1936.

32 C. Tsai, R. J. Tseng, Y. Yang and C. S. Ozkan, J. Nanoelectron. Optoelectron., 2008, 3, 133-136.

33 R. J. Tseng, C. L. Tsai, L. P. Ma and J. Y. Ouyang, Nat. Nanotechnol., 2006, 1, 72-77.

34 A. Klug, Philos. Trans. R. Soc. London, Ser. B, 1999, 354, 531-535.

35 E. Royston, S. Y. Lee, J. N. Culver and M. T. Harris, J. Colloid Interface Sci., 2006, 298, 706-712.

36 X. N. Wang, Z. W. Niu, S. Q. Li, Q. Wang and X. D. Li, J. Biomed. Mater. Res., 2008, 87A, 8-14.

37 A. M. More, J. L. Gunjakar and C. D. Lokhande, Sens. Actuators, B, 2008, 129, 671-677.

38 Y. Shimizu, T. Okamoto, Y. Takao and M. Egashira, J. Mol. Catal. A: Chem., 2000, 155, 183-191.

39 H. Tai, Y. Jiang, G. Xie, J. Yu and X. Chen, Sens. Actuators, B, 2007, 25, 644-650. 